\title{
Sulfate Resistance of Blended Cements (Limestone Illite Calcined Clay) Exposed Without Previous Curing
}

\author{
Agustín Rossetti $^{1}$, Tai Ikumi ${ }^{2}$, Ignacio Segura ${ }^{2}$ and Edgardo F. Irassar ${ }^{3}$ \\ ${ }^{1}$ Comisión de Investigaciones Científicas de la Provincia de Buenos Aires, CICPBA- LEMIT, La \\ Plata, Argentina. email: agustin.rossetti@ing.unlp.edu.ar \\ ${ }^{2}$ Department of Civil and Environmental Engineering, Universitat Politècnica de Catalunya Barcelona \\ Tech, Jordi Girona 1-3, C1, E-08034 Barcelona, Spain. \\ ${ }^{3}$ Facultad de Ingeniería, CIFICEN (UNCPBA-CICPBA-CONICET), B7400JWI Olavarria, Argentina. \\ email: firassar@fio.unicen.edu.ar
}

\begin{abstract}
Durability in aggressive environments is an important factor to extend the service life of concrete and the use ternary blended cements (limestone filler + calcined clays) can contribute to this purpose. In sulfate environments, the effects of supplementary cementing materials depend on the concentration, Portland cement and the progress of hydration reactions. Low level of limestone filler replacement influences the stabilization of AFt due to formation of monocarboaluminate, but high replacement increases the effective $w / c$ and the capillary porosity promoting sulfate penetration. The use of active pozzolans suppresses the sulfate attack by minimizing both ettringite and gypsum formation. It is generally assumed that curing prior to sulfate exposure should be extended to allow the development of the pozzolanic reaction and subsequent reduction of portlandite content, pore size structure refinement and permeability reduction. However, in most field applications, concretes exposed to sulfate attack are cast in situ and thus, these are exposed to sulfate since early ages. This paper evaluates the sulfate resistance of an illitic-calcined clay and limestone filler when the cement is exposed immediately to aggressive environments. In this paper, the external sulfate resistance of blended cements containing 30\% replacement of limestone filler and/or calcined clay (C30F, C30CC and C15F15CC) are analysed. Two different calcined clays from Buenos Aires, Argentina were selected. Mortar prisms and cement paste cubes were fabricated and exposed to a sodium sulfate solution after 2 days. Comparison of sulfate resistance was based on the expansion, mass variation, visual appearance and compressive strength. Furthermore, the evolution of microstructure of blended cements exposed to sodium sulfate solution was characterized by XRD tests on the external surface and the core of cementblended pastes.
\end{abstract}

Keywords: Illite Calcined Clay, Limestone Filler, Sulfate Attack, Curing, Early Exposure.

\section{Introduction}

Illite is one of the most abundant clayed minerals of the earth's crust coming from the alteration of feldspars and micas of rocks due to the weathering process. Illite clays develop pozzolanic properties when are thermally treated at $950{ }^{\circ} \mathrm{C}$ (Lemma et al, 2015) causing dehydroxylation and collapse of its structure to form a metastable or amorphous aluminosilicate (Ramachandran, 1995). These pozzolanic properties combined with the large availability of this mineral place illite calcined clays as a key supplementary material for the future mineral admixtures used in concrete.

Despite the promising characteristics of calcined clays described, a safe introduction of these 
materials in the concrete technology requires the assessment of other aspects, such as the durability against different aggressive environments. External sulfate attack (ESA) has been recognized as a complex degradation phenomenon that may cause severe damage in cement based materials (Neville, 2004). High resistance to ESA in $\mathrm{Na}_{2} \mathrm{SO}_{4}$ solutions is normally associated with a segmented pore structure and low levels of portlandite $(\mathrm{CH})$ and aluminate phases available to limit sulfate ingress and ettringite formation (Wild et al, 1997). Another important issue hardly ever evaluated for ESA resistance is the early sulfate exposure. In reality, the source of external sulfate ions is usually found in sulfate-rich soils and underground waters in contact with concrete. Therefore, ESA is especially significant in underground structures like foundations, tunnels or waste containers. Due to their large size, these structures are usually build in situ, hence being exposed to sulfates since casting. However, currently most studies about the ESA performed in laboratory rely on testing specimens cured several days in lime water prior to immersion in the aggressive sulfates solution (Ikumi et al, 2017).

The aim of this paper is to make a comparative study of the performance of blended cements with the addition of filler and two different illite calcined clays against sulfate attack without the previous curing prescribed by the standards to evaluate sulfate resistance when supplementary materials are used. Different proportions of cement, filler and calcined clay were used to make pastes and mortars to evaluate the mineralogical changes (X-Ray diffraction) and the evolution of physical and mechanical properties (mass variation, visual aspect, expansion and compressive strength) during ESA.

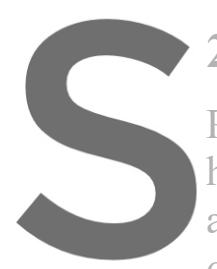

\section{Materials and \\ Portland cement (CEM \\ high purity calcite (LF) \\ are identified by their
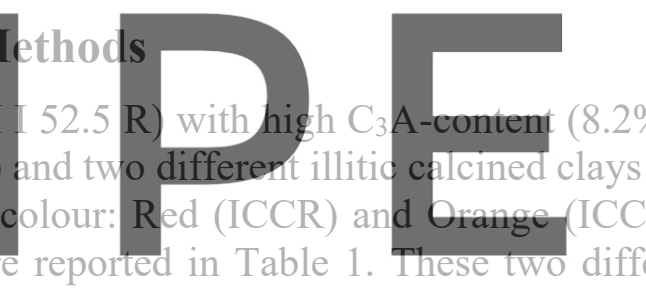

determined by XRF are report in Table 1 .

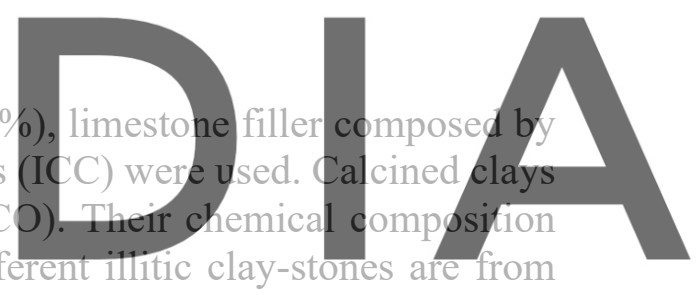

quarries near to Olavarria, Buenos Aires Province (Argentine) and were calcined in oven at 950

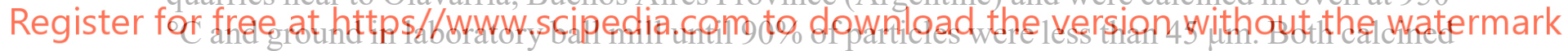

clays meet the chemical requirements for Class N pozzolan (ASTM C 618): $\mathrm{S}+\mathrm{A}+\mathrm{F}>70 \%$;

SO3 $<4 \%$ and LOI $<10 \%$. XRD analysis reveals low intensity peaks of dehydroxilated ilitite in both clays and the associated minerals are quartz and hematite for ICCR and, quartz, hematite, oligoclase and spinel for ICCO. For these two ICCs, the Frattini test was positive after 14 days. Additionally, strength tests were performed and presented in another publication (Lemma et al, 2015).

Table 1. Chemical composition and mass loss on ignition of cement, filler and ICC, \%.

\begin{tabular}{cccccccccc}
\hline Material & $\mathbf{C a O}$ & $\mathrm{SiO}_{2}$ & $\mathrm{Al}_{2} \mathrm{O}_{3}$ & $\mathrm{Fe}_{2} \mathrm{O}_{3}$ & $\mathrm{MgO}$ & $\mathbf{S O}_{3}$ & $\mathrm{~K}_{2} \mathrm{O}$ & $\mathrm{Na}_{2} \mathrm{O}$ & LOI \\
\hline Cement & 60.92 & 16.58 & 4.21 & 1.80 & 2.16 & 1.77 & 0.67 & 0.28 & 2.05 \\
\hline Filler & 59.53 & $<0.01$ & 1.10 & 0.52 & 0.48 & 0.06 & 0.060 & $<0.01$ & 39.98 \\
\hline ICCR & 0.33 & 66.30 & 16.28 & 9.23 & 1.46 & $<0.01$ & 5.60 & 0.08 & 0.58 \\
\hline ICCO & 1.13 & 63.43 & 13.82 & 7.89 & 2.71 & 0.04 & 4.29 & 1.52 & 0.2 \\
\hline
\end{tabular}


Physical characteristic of the materials are summarized in Table 2. Density was determined by the ASTM C 188 procedure, retained on 75 and $45 \mu \mathrm{m}$ sieves (ASTM D 422 and C 618) and Blaine specific surface (ASTM C 204) and the particle size distribution (PSD) were determined using the laser granulometer (Malvern Mastersizer, 2000). The particle size distribution by volume of materials are shown in Figure 1.

Table 2. Physical characteristic of cement, clays and filler.

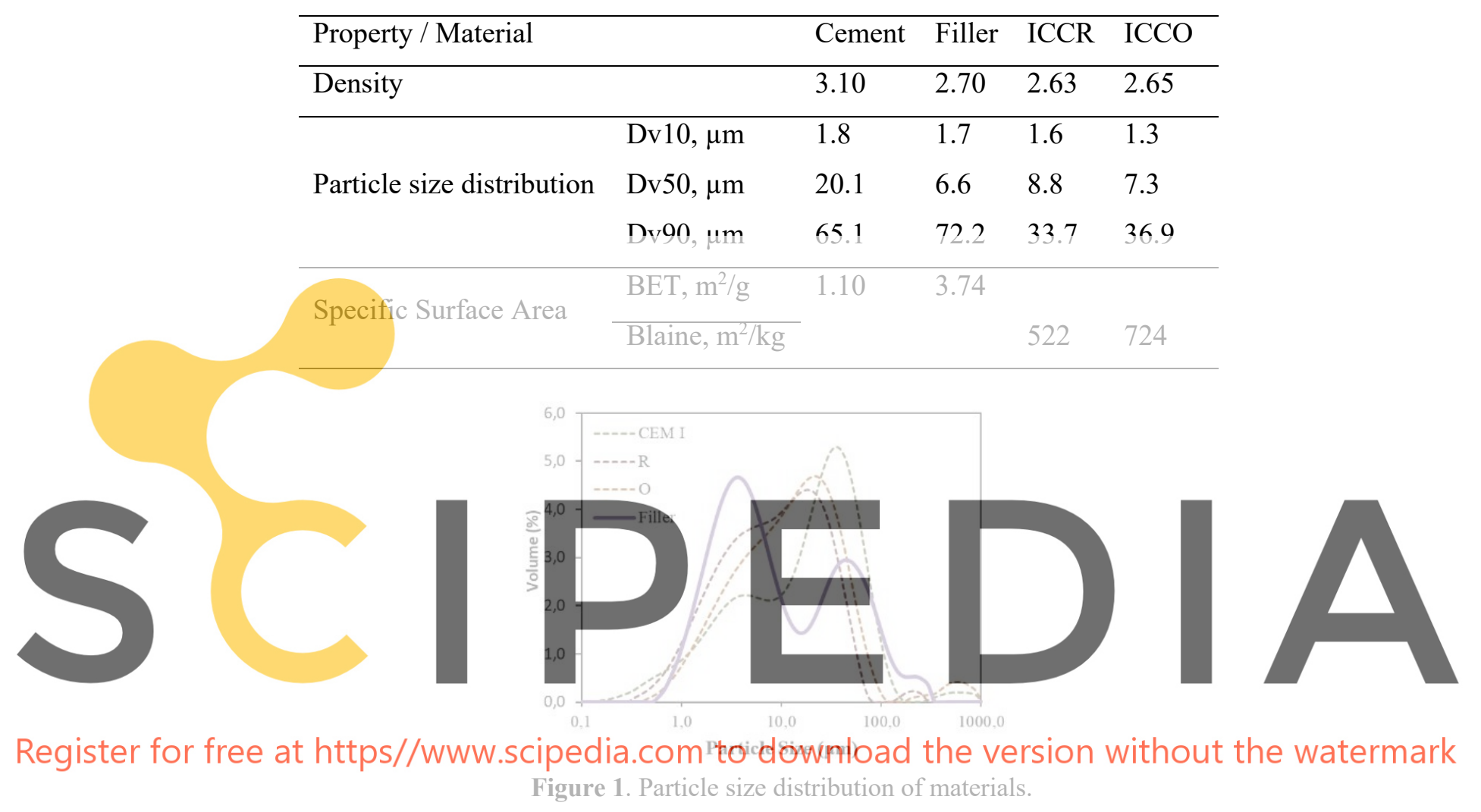

For this study, the SCMI repiacement in all binders was set to $30 \%$ by cement weight. By this way, all compositions present the same initial $\mathrm{C}_{3} \mathrm{~A}$ content and thus, the different behaviours observed can be solely attributed to the effects of the SCMs introduced. Five different blended cements were prepared: a binary filler cement $(70 \% \mathrm{CEM}+30 \% \mathrm{LF})$, a binary illitic red calcined clay cement $(70 \% \mathrm{CEM}+30 \%$ ICCR $)$, a binary illitic orange calcined clay cement $(70 \% \mathrm{CEM}+30 \% \mathrm{ICCO})$, a ternary red illitic blended cement $(70 \% \mathrm{CEM}+15 \% \mathrm{ICCR}+15 \%$ LF) and a ternary orange blended cement $(70 \% \mathrm{CEM}+15 \% \mathrm{ICCO}+15 \% \mathrm{LF})$. The nomenclature adopted is $\mathrm{C} 30 \mathrm{~F}, \mathrm{C} 30 \mathrm{CCR}, \mathrm{C} 30 \mathrm{CCO}, \mathrm{C} 15 \mathrm{~F} 15 \mathrm{CCR}$ and $\mathrm{C} 15 \mathrm{~F} 15 \mathrm{CCO}$, respectively.

Pastes were prepared using a water to binder ratio of 0.485 (as prescribed by ASTM C1012) and mixed using high speed mixer. Eighteen cubes of $20 \times 20 \times 20 \mathrm{~mm}$ were cast for each blended cement and cured in moist cabinet. After 24 hours, cubes were demolded and immersed in water for 24 hours to ensure full saturation of the samples prior to sulfate exposure. Then, twelve cubes were immersed in $50 \mathrm{~g} / 1 \mathrm{Na}_{2} \mathrm{SO}_{4}$ solution and the remaining cubes in water at 20 ${ }^{\circ} \mathrm{C}$. At 7, 14, 28, 56, 96 and 204 days, the change of mass and the visual appearance was evaluated. Both sulfate solution and water were replaced after each determination.

Changes in phase composition were examined using X-ray diffraction (XRD) at 28 and 204 
days. Surface and core samples of the same size were cut from the paste cubes, dried by solvent exchange with acetone, crushed and the powder was pressed in cylindrical standard sample holders of $16 \mathrm{~mm}$ diameter and $2.5 \mathrm{~mm}$ height. XRD measurements were made using a PANalytical X'Pert PRO MPD Alpha $\Theta / 2 \Theta$.

The evaluation of expansions during sulfate exposure was based on the mortar bar expansion tests defined by the ASTM C 1012. Mortar specimens of 25 × 25 x $297 \mathrm{~mm}$ elaborated with $\mathrm{w} / \mathrm{c}=0.485$ and cement:graded sand $=1: 2.75$ were cast. Before sulfate immersion, the standard proposes a $24 \mathrm{~h}$ curing in molds at $38^{\circ} \mathrm{C}$ and further curing after demolding in lime water until the compressive strength reaches $20 \mathrm{MPa}$. For this experience, the initial curing was made in the molds during 24 hours in a moist cabinet at $20^{\circ} \mathrm{C}$. After one day, the specimens were demolded and immersed in lime-water at $20^{\circ} \mathrm{C}$ during 24 hours. Finally, the initial length was measured and the bars were immersed in the $0.352 \mathrm{M} \mathrm{Na}_{2} \mathrm{SO}_{4}$ solution $(50 \mathrm{~g} / \mathrm{l})$ at $20^{\circ} \mathrm{C}$. The expansion was determined at 7, 14, 21, 28, 56, 91, 105, 120 and 180 days and the solution was renewed after each measurement period. Reported expansions are the average of six specimens. According to ASTM C 1157, blended cement is sulfate resistant (HS) when the expansion does not exceed $0.05 \%$ at 6 months and $0.10 \%$ at 1 year.

For compressive strength, mortars bars were cast following the procedure described above and eut with diamond saw in $25 \mathrm{~mm}$-cubes before immersion in the sulfate solution. Complementary, a set of 12 cubes continues curing in lime-water. These cubes allow comparing change mass and compressive strength on the specimens with the same dimension when they were exposed to sulfate solution.

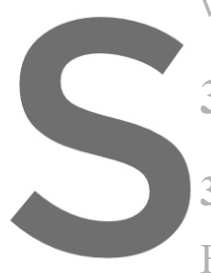

3 Results and Discussion

3.1 Mass Variation of Paste
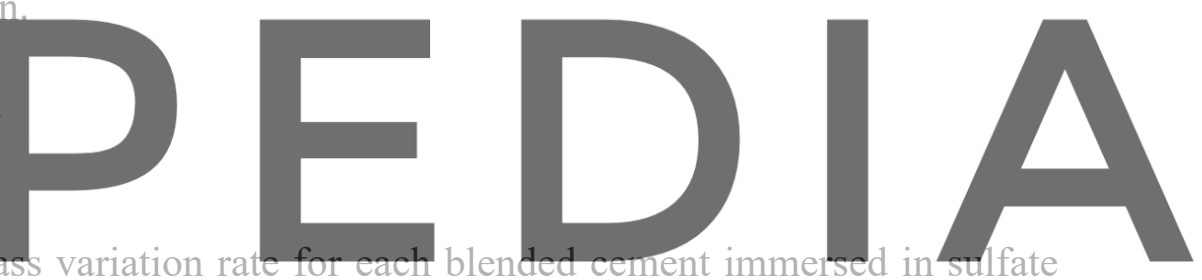

solution (grey-red-orange) and in water (blue bar) during 6 months. As can be seen, all pastes

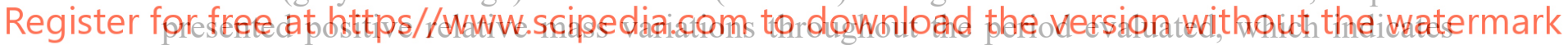
increments of mass during the attack. However, this mass increment is produced at different rates depending on the binder composition. During the first 28 days, all specimens follow similar trends, with a gradual decrease on mass gain over time, regardless of the binder and the exposure condition. This behaviour is associated with the pore filling caused by normal hydration processes, relevant here as the samples were immersed only 2 days after casting.

After 28 days, the specimens submerged in non-aggressive conditions maintain similar mass variation rates until the end of the test, as the main hydration reactions occur during the first weeks. However, the samples stored in sulfate solution show an increase of mass gain from this age, which is more significant in the composition $\mathrm{C} 30 \mathrm{~F}$, followed by the $\mathrm{C} 15 \mathrm{~F} 15 \mathrm{CC}$ (more in $\mathrm{R}$ than $\mathrm{O}$ ) and $\mathrm{C} 30 \mathrm{CC}$ (again more in $\mathrm{R}$ than $\mathrm{O}$ ). This mass gain observed after 28 days of aggressive curing is associated with the sulfate uptake and the progressive formation of sulfate attack compounds such as gypsum and ettringite. These results suggest that the use of calcined clay reduces the amount of sulfate ions penetrating the matrix and delays the formation of expansive phases. The higher weight gain over time in pastes with ICCR versus ICCO could be attributed to a different interaction of the red calcined clay with sulfates than the orange calcined clay, but this interaction would not be related to greater damage. 

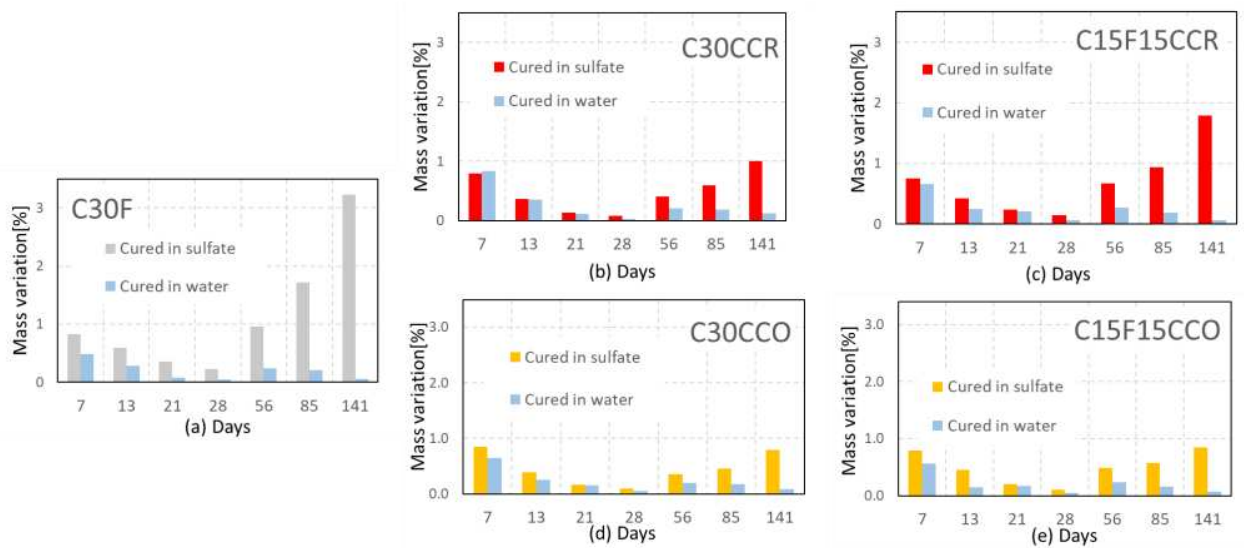

Figure 2. Relative mass variation of pastes cured in water and in sulfate solution.

\subsection{Visual Appearance of paste}

Figure 3 shows the evolution of visual appearance of paste cubes immersed in sulfate solution for some selected photographs at 28, 90 and 180 days. Figure 3 shows that the integrity of cubes for all blended cements is not compromised during the first 28 days of sulfate exposure. At 90 days, C30F presents a remarkable cracking along the edges, which is the typical cracking pattern associated with the ESA. At this age, pastes with ternary cements (C15F15CCO and

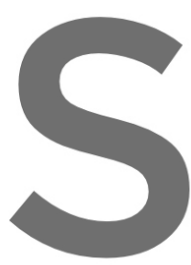
C15F15CCR) show a slight cracking near the corners of the cubos, being its intensity considerably lower than for $\mathrm{C} 30 \mathrm{~F}$. On the other hand, the composition with $30 \% \mathrm{ICC}$ no signs of damage after 90 days of sulfate exposure, but for the $30 \%$ of I
can be seen at the edge. At 180 days, $630 \mathrm{~F}$ cubes are completcly cracked as the and regions close to the corners can be easily she for free at https wasw schpedia com to download the version without the watermark the edges, being slightly more developed in C30CCO pastes. These results suggest that the incorporation of calcined clays up to a $30 \%$ replacement limit significantly more the amount of cracking developed during the ESA than the use of limestone filler.

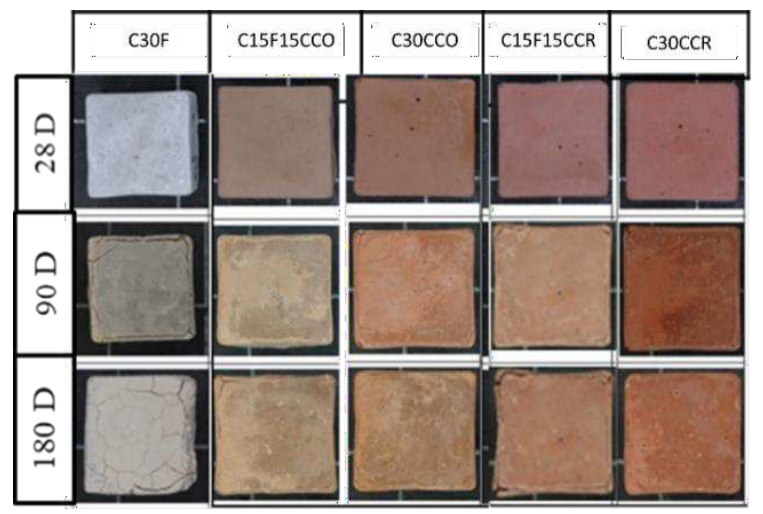

Figure 3. Visual appearance of paste: photographs of cubes at 28, 90 and 180 days. 


\subsection{XRD-Analysis of Pastes}

Figure 4 shows the XRD patterns obtained from the surface and core samples of the paste cubes exposed to sulfate attack at 204 days. On the surface (Fig. 4a), ettringite and gypsum formation are detected in all samples. Peaks of ettringite and gypsum were more intense for C30F. In this paste, gypsum is confirmed by the presence of peak at $20.72^{\circ} 2 \theta$. For paste containing $15 \%$ of ICC, a hump before the quartz peak at $20.82^{\circ} 2 \theta$ is detected; also, the high peak intensity at $31.16^{\circ}$ and $33.36^{\circ} 2 \theta$ is attributed to gypsum. For C30CCR and C30CCO pastes, the hump and secondary peak of gypsum have a weak intensity, and some doubt to assign completely the $11.63^{\circ}$ and $23.3^{\circ} 2 \theta$ peaks to gypsum arise due to a possible mismatched with the monocarboluminate. In the core of the cubes (Fig. 4b), ettringite and monocarboaluminte were assigned as the peak hump at $20.7^{\circ} 2 \theta$ is absent, the peak intensity at 31.16 and $33.36^{\circ} 2 \theta$ were too weak. In addition, the intensity of $\mathrm{CH}$ peaks were too large in the core of the specimens, indicating its consumption on the surface to from ettringite and gypsum. Some reduction of $\mathrm{CH}$ is attributed to the pozzolanic reaction of illite calcined clays.
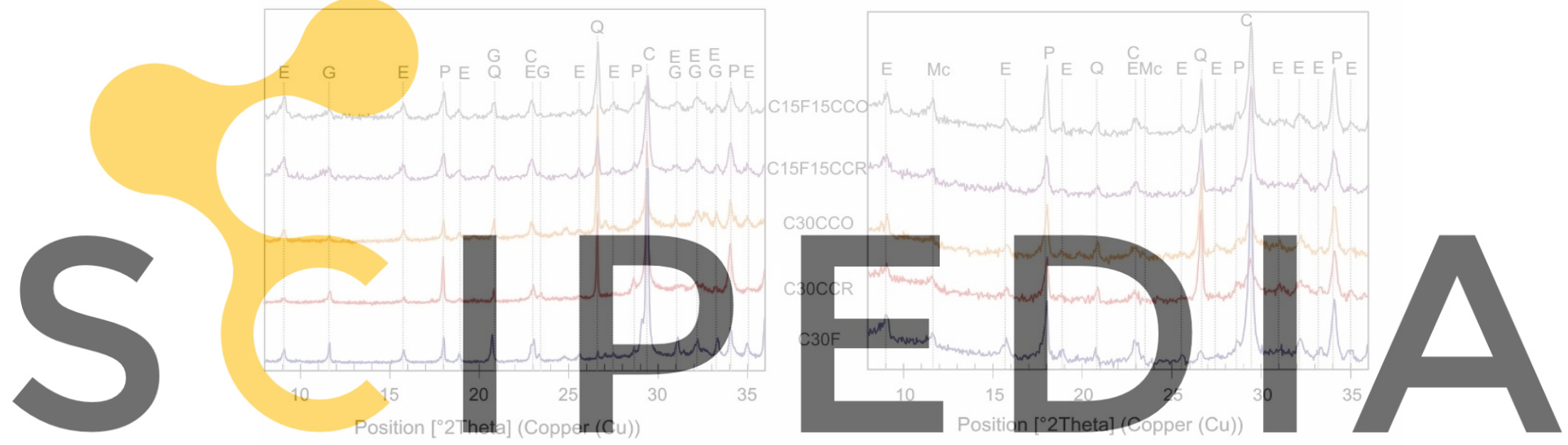

Figure 4. XRD pattern on pastes exposed to sulfate solution for 204 days. (a) Surface and (b) Core.

Register for free at https//www.scipedia.com to download the version without the watermark 3.4 Expansion of Mortar

Expansions of mortar bars in sulfate solution are shown in Fig. 5. During the initial exposure up to 28 days, the expansions of the five blended cements present a similar rate, being slightly higher for $\mathrm{C} 30 \mathrm{~F}$. After 28 days, the $\mathrm{C} 30 \mathrm{~F}$ expansion rate increases exponentially reaching the limit of $0.10 \%$ at 38 days. At 90 days, the attack on $\mathrm{C} 30 \mathrm{~F}$ has been so severe that it is no longer possible to measure the length variations since the specimens are practically disintegrated.

On the other hand, C30CCR mortars show a very slow expansion rate and the limit of $0.05 \%$ is only reached at 252 days, which is after the threshold of 6 months established by the ASTM standard to be considered as a sulfate resistant cement. For the $\mathrm{C} 30 \mathrm{CCO}$ the expansion is also lower but the limit of $0.05 \%$ is overpassed at 3 months, so this blended cement is not sulfate resistance according to the standards. The low expansion when $30 \%$ of ICC (O and R) is mixed with the cement is attributed to the pozzolanic reaction of the calcined clays, which consumes the $\mathrm{CH}$ formed during hydration and reduce the availability of calcium for ettringite formation and specially blocking the pores to prevent the ingress of sulfates into the matrix. This pozzolanic reaction progresses after the immersion in the sulfate solution as occurred in nonaggressive water curing. 
For C15F15CCR mortar, the expansion is similar to C30CC up to 90 days, but from this point, the slope increases and exceeds the limit of $0.10 \%$ at 161 days, qualifying this cement as not sulfate resistant. The C15F15CCO mortar, the expansion is similar to C30CC up to 56, then the expansion grows faster than the other ternary cement and the limit of $0.05 \%$ is passed at this age. Here it can be seen that the ICCR has better pozzolanic activity than the ICCO, because it produces lower expansion on sulfate for the binary and ternary cements.
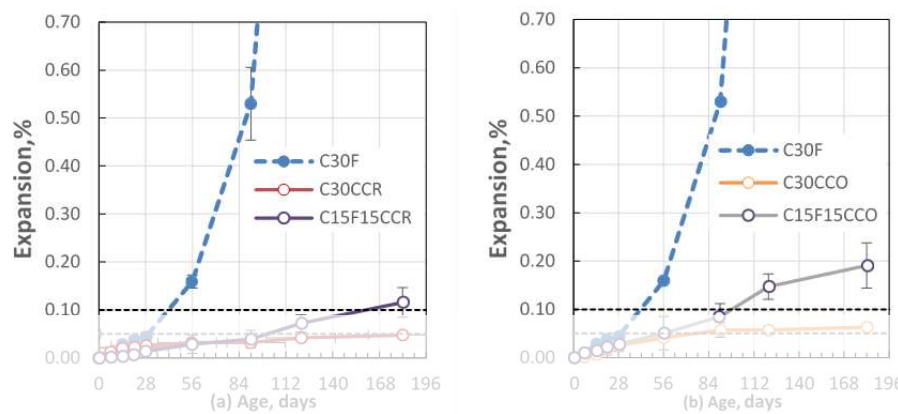

Figure 5. Expansion on sodium sulfate of mortar following ASTM 1012. (a) Blended cements with ICCR and (b) blended cements with ICCN.

\subsection{Compressive Strength}

Figure 6 shows the compressive strength of mortar for blended cements immersed in sulfate solution (Fig 6 a and $\mathbf{c})$ compressive strength o 28 to 90 days confirm increase due to the dilut At 90 days, C30F cured in sulfates has practically lost its
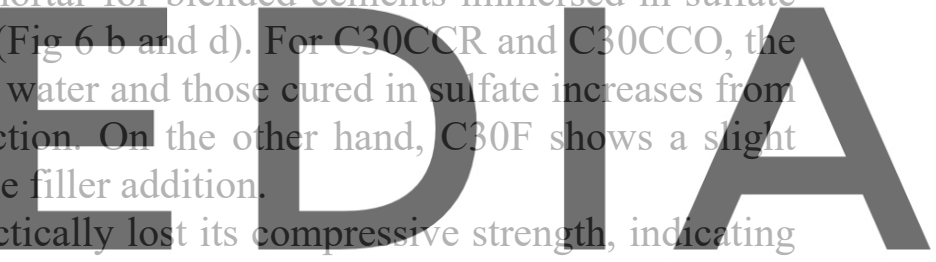

severe degradation caused by ESA. Compositions with the $30 \%$ ICC replacement (C30CCR

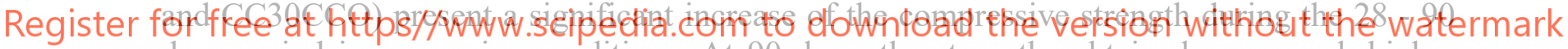
days period in aggressive conditions. At 90 days, the strengths obtained even reach higher values than the ones obtained in non-aggressive conditions. This behaviour might beattributed to ettringite formation in quantities below the damage onset threshold, which only causes a densification of the matrix. Mixtures with $15 \%$ ICC replacement also develop strength improvements from 28 to 90 days. However, in this case the strength gained is lower than the one observed in $30 \%$ ICC replacement mixtures, specially in the ICCO material.
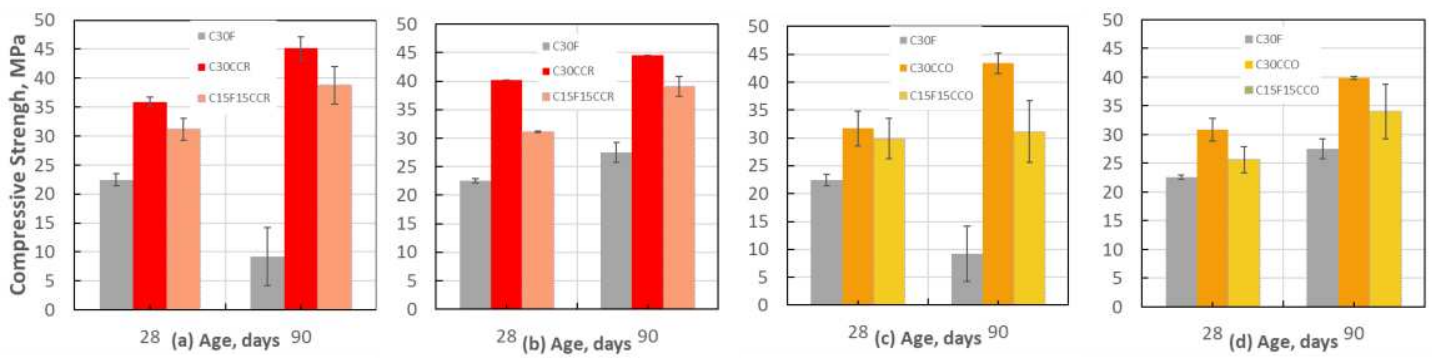

Figure 6. Compressive Strength of mortars, (a) C30CCR, C15F15CCR cured in sulfate, (b) C30CCR, $\mathrm{C} 15 \mathrm{~F} 15 \mathrm{CCR}$ cured in water, (c) C30CCO, C15F15CCO cured in sulfate, (d) C30CCO, C15F15CCO cured in water. 


\section{Conclusions}

Preliminary results of this study related to the sulfate attack with limestone filler and two different illitic calcined clay exposed immediately to the aggressive environment shows that:

- Limestone filler addition to Portland cement causes the formation of monocarboaluminate, which is unstable in sulfate environment and rapidly forms ettringite causing cracking and massive influx of sulfate ions promoting the gypsum formation, expansion and compressive strength reduction.

- The pozzolanic reaction of calcined clay in mortars is similarly developed in aggressive and non-aggressive curing conditions, consuming the $\mathrm{CH}$ and blocking the sulfate ingress due to pore size refinement. The AFm phases formed during hydration in water were converted to ettringite when pastes are exposed to sulfate solution, but the mortar shows no expansion and retains the compressive strength at 6 months.

- These experiences show that despite the lack of curing prior to sulfate exposure, cement with the replacement of $30 \%$ of an illitic calcined clay (in this case the ICCR better than ICCO) shows great resistance to ESA, while limestone cements presented a worse performance.

\section{ORCID}

Agustin Rossetti: https://orcid.org/0000-0002-0809-2320

Tai Ikumi: https://orcid.org/0000-0001-9547-5241

Igancio Segura: https://orcid.org/0000-0001-6519-9899

Edgardo Irassar: https://orcid

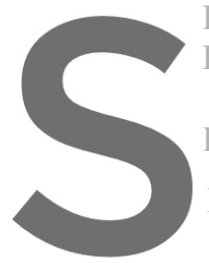

References

Ikumi, T., Segura, I. and Cavalad development of mortars.
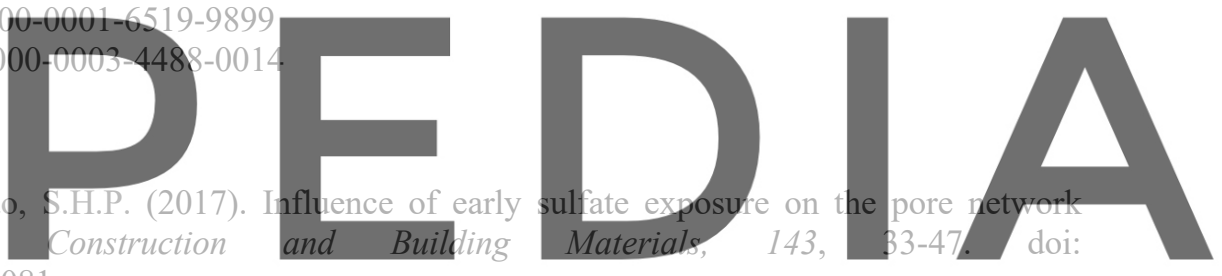

10.1016/i.conbuildmat.2017.03.081

Lemma, R., Irassar, E.F. and Rahhal, V..(2015). Calcined illitic clays as portland cement replacements. In K.

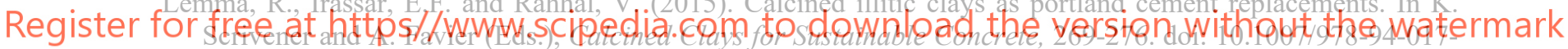
9939-3 33

Neville, A. (2004). The confused world of sulfate attack on concrete. Cem. Concr. Res. 34

Ramachandran, V.S. (1995). Concrete Admixtures Handbook: Properties, Science and Technology. 2nd ed, ed. V.S. Ramachandran. United States of America: Noyer Publication

Wild, S., Khatib, M. and O'Farrell, M. (1997). Sulphate resistance of mortar, containing ground brick clay calcined at different temperatures. Cem. Concr. Res., 27, 697-709. doi: http://dx.doi.org/10.1016/S00088846(97)00059-8 